\section{Whaling: quota trading won't work}

Anti-whaling organizations are often presented as conservationists (Nature 481, $114 ; 2012)$. But for conservation efforts to advance, we need to resolve the differences between animal welfare, which is concerned with individuals, and environmental conservation, which focuses on maintaining populations, species and ecosystems.

Anti-whaling organizations spend millions of dollars every year trying to stop the Japanese whaling fleet from hunting the common minke whale (Balaenoptera acutorostrata), which is not endangered (Nature 481, 139-140; 2012). Their use of financial resources is justifiable only from an animalwelfare perspective.

If the anti-whaling lobby were interested in whale conservation, it would use its financial power to help to assess the population ecology and dynamics of the many whale species listed as 'data deficient' by the International Union for Conservation of Nature. This would enable evidence-based quotas to be set for countries that choose to exploit this resource.

The quota-trading scheme proposed by Christopher Costello and his colleagues is a promising market-based solution for whale conservation, but is unlikely to succeed. For some countries, such as Japan, whaling is a symbol of national and cultural identity, so the economic returns may not provide sufficient incentive. Also, this is strictly a moral issue for the anti-whaling lobby, driven not by environmental conservation but by the suffering imposed on individual whales.

Over the past decade, the two sides have grown further apart. If a compromise is to be reached, environmental conservationists must inform decision-makers and public opinion in the same way that the anti-whaling lobby has used its financial muscle to push its agenda over the years. Diogo Veríssimo, Kristian Metcalfe Durrell Institute of Conservation and Ecology, University of Kent, Canterbury, UK.dv38@kent.ac.uk

\section{Scientists cannot compete as lobbyists}

Suggestions that scientists should run for political office or campaign to promote their work are counterproductive and ultimately self-defeating (Nature 480, 153; 2011). Science needs a permanent pipeline into policy, not temporary windows cracked open by individual researchers.

Lobbying takes time and money: more than US $\$ 3.5$ billion was spent in 2010 on lobbying US Congress members. Academic scientists simply cannot compete on that scale.

Scientists must be impartial arbiters of data, not political agents. They need to be able to negotiate with governments, irrespective of their political hue, and to advise politicians in a useful and timely way.

Scientific-liaison offices would give scientists an apolitical route to policy formation. These would have a cross-ministerial mandate to make research results accessible and enable politicians and policy-makers to reach informed decisions.

When politicians ignore science, it is a failure of our system of governance rather than of individual scientists to act as lobbyists for their research.

Brett Favaro Simon Fraser University, Burnaby, British Columbia, Canada. bfavaro@sfu.ca

\section{Expand Australia's sustainable fisheries}

We do not believe that marine protected areas (MPAs) currently offer effective conservation in
Australia. They do not address pollution or climate change (Nature 480, 151-152; 2011), and overfishing there has largely been rectified. MPAs are also inadequate for managing the major threat of introduced organisms, of which more than 400 have already been identified in Australian waters.

Terry Hughes' call to protect coral reefs from catch-and-release fishing (Nature 480, 14-15; 2011), by closing a further 480,000 square kilometres of ocean in Australia's Coral Sea in addition to the adjacent $507,000 \mathrm{~km}^{2}$ already proposed, is an example of exaggerated restriction of fishing. We contend that sustainable fisheries need to be expanded, not restricted.

Australia has well-managed fisheries but imports more than $70 \%$ of its seafood. By continuing to import while closing more of its exclusive economic zones to fishing, Australia is diverting pressure on seafood resources and the responsibility for their sustainable exploitation to other countries, most of which do not have Australia's effective governance of fishing.

Robert Kearney University of Canberra, Australia.

bob.kearney@canberra.edu.au Graham Farebrother Institute for Marine and Antarctic Studies, University of Tasmania, Australia.

\section{Use snail ecology to assess dam impact}

It is not yet clear whether dam construction in the Mekong Basin will increase the impact of schistosomiasis in the region (A. R. Blaazer Nature 479, 478; 2011). We need a better understanding of the parasite's transmission ecology to improve disease prediction and to determine the best dam locations.

Comparisons with dams in other countries can be misleading. In Africa, schistosome parasites are transmitted by snails with different habitat requirements from Neotricula aperta, a snail that is found only in calciumrich waters in the Mekong Basin and the sole intermediate host of Schistosoma mekongi.

In fact, densities of N. aperta have declined to undetectable levels downstream of the Nam Theun 2 dam in Laos (S. W. Attwood et al. Ann. Trop. Med. Parasitol. 98, 221-230; 2004) - possibly as a result of flooding, decreased calcium levels and silting. Densities are also falling farther downstream in Thailand, even though habitats there are apparently unaffected (my unpublished observations). Stephen W. Attwood Sichuan University, Chengdu, China. swahuaxi@yahoo.com

\section{Asian medicine: a way to compare data}

To help to integrate traditional Asian medicine with Western medicine (S. Cameron et al. Nature 482, 35; 2012), the World Health Organization (WHO) is developing common systems for collecting statistics from both. This information - known as the International Classification of Traditional Medicine (see go.nature.com/ mv3iux) - is being incorporated into a revision of the $\mathrm{WHO}$ International Classification of Diseases, to be released in 2015.

Clean, standardized data from several countries will allow proper comparison of the effectiveness, cost and safety of the different approaches.

Kenji Watanabe, Xiorui Zhang, Seung-Hoon Choi WHO ICTM Project Team, Center for Kampo Medicine, Tokyo, Japan. watanabekenji@a6.keio.jp

CONTRIBUTIONS

Correspondence may be sent to correspondence@ nature.com after consulting the guidelines at http:// go.nature.com/cmchno. 